\title{
Dominant values of professional development education spaces of cross-border regions in the aspect of postmodernism
}

\author{
Nadezhda Bulankina ${ }^{1, *}$, Natalja Malahova ${ }^{1}$, Ekaterina Egorova $^{2}$, Anna Seredintseva ${ }^{3}$ and \\ Valentina Tsybaneva ${ }^{4}$ \\ ${ }^{1}$ Novosibirsk Institute of Professional Skills Improvement and Vocational Retraining of Education \\ Workers, 630007, Novosibirsk, Russia \\ ${ }^{2}$ Don State Technical University, 1 Gagarin sq., Rostov-on-Don, Russia \\ ${ }^{3}$ Volgograd State University, 404130, Russia \\ ${ }^{4}$ Moscow City University, 105064, Moscow, Russia
}

\begin{abstract}
Based on an extensive review of the current literature and research in terms of axiological approach, this article considers the strategies of post-modernism pluralistic concepts of socio-culture spaces, and discusses the ideas of andragogy supporting the value sphere of the individual of pedagogues, FLT teachers, who are responsible for the creative education development spaces in the classrooms. As a result of the study the authors present a comprehensive model of course design elements as a theory for guiding the use of new technologies in distance education through culture-oriented pedagogical strategies and activities. In conclusion there discussed some of the fruitful examples of the Tutorials in a polyculture \& polylingua situation and event spaces of cross-border regions of Russia, in terms of mentoring and fostering a culure-determined learning and a selfdetermining individual.
\end{abstract}

\section{Introduction}

Value dominants as an integrative corpus of instructional elements of the individual in the culture environments that compose the education spaces within the frameworks of the society of the postmodern epoch of pluralism of thinking, opinions, ideas, etc [1], where any viewpoints can be visualized by realizing them, are considered to be an important identification sign/criteria of validity of a realia, and for the individual in the globalizing world. Dominant value priorities serve, first and foremost, as a significant cement component for the development of the individual for whom patriotism, national identity, culture and education, self-realization are of primary importance in life, in his/her professional career $[2,3]$. Although we can observe, time and again, contradictory education projects, low results in instructional institutions, we see the way out in real positive motivation for culture selfdetermination and self-learning of man via life. Due to the specifics of CSD the individual is open to innovations and doable to better life around $[2,4,5,6,7,8]$. The culture mission of an educator is great, and needs support from the government and the society $[9,10]$. These issues

\footnotetext{
*Corresponding author: nebn@yandex.ru
} 
compose the problem statement and the area for discussion and reconstruction in terms of axiological approach that considers different cultural aspects of modern professional career of an educator, both academics and practitioners $[11,12,13,14]$.

As is the case, there is growing interest, of both domestic and overseas current Scholarship, in value priorities research and the process by which it can be enhanced. More and more novel initiatives launched by our government and instruction organizations are aimed to modernize public services for providing new opportunities to adult citizens and social organizations $[4,7,9,11]$. They are in need of mechanisms to ensure compliance with axiological standards, value dominants, traditions and procedures. Adult and teachers education research in Russia continue to gain the attention of state and public communities due to the need to improve the value component of education among adult learners, in our case, schoolteachers of different subjects, who are to foster value dominants of school youths in the school classrooms.

The appeal to the results of current Scholarship show their concern for the self-determined and self-learning issues as a value in the aspect of the individual development trajectory of culture self-determination and self-identification of the pedagogue in a cross-border region characterized with abrupt and unpredictable speech and linguistic behavior of the people who come from other regions and cross-border states to live, work and study $[4,6,12,13]$. However, in many workshops and training sessions involving academics and practitioners, i.e. FLT (Foreign Language Teaching) schoolteachers, much of the discussions on these issues in data collection and research volumes are not to the point of adequate attention that it requires. And in this sense, different reports, state documents and discussions indicated the need for investing in technologies to offer better educational services to the target audience composed of academics and practitioners working in the field of teaching, training and talent development, and for better understanding of the instructional development spaces under implementation support in terms of subject concept; state standards, national projects on education", etc, By the same token, their goal is seen in reduction of the burden for pedagogues [1, p. 40]. These documents point out interpretation and implementation of these main directions of development of the society and the personal development in the information and education spaces, in particular. This trend named recurrent education and continuing personalized education or life-long education of adults via novel Pedagogy, Open Space Technology (elearning and remote learning), and Content Knowledge [1; 3; 5, 7, 8, 9, 13] has been promoted by important Russian education organizations as Ministry of Instruction, Institutions of In-Service and Upgrading of educational workers, and Universities, in terms of their professional skills and competences through the Tutorials $[1,8,10,13,14]$. So, this article provides a basis for discussion and research into andragogy as a theory for guiding the use of new communication technologies in recurrent professional education of a pedagogue.

The purpose of this article is seen in the analysis of the Tutorials as a crucial support for pedagogues, FLT teachers, in the frameworks of distant education that needs updating objectives, and providing culturally oriented humanitarian practices to develop both professionals, and main conditions for culture self-determination of the individual who is able to use critical thinking to understand social situations, dominant national values in life, and other people' viewpoints as a value; to choose professional career for self-realization and self-improvement as a value, etc. 


\section{Concept and methodology of the study}

The empirical array is supported by the concept according to which methodological aspects of the education problems under discussion in terms of new education philosophy based on post-modernizm ideas (globalization, information space, macro-paradigm, rhizoma learning, strategic discourse, deconstruction of classical education, pluralism of activities, technologies and knowledge content, etc.) are associated with the purpose of this research to clarify and adjust the authors' axiological culture-oriented model of the individual development trajectory in the recurrent system of the new challenges education spaces of human existence in the world of modernity. The examples of the Tutorials are discussed from the view point of their implementation and provision in the information and education spaces covered by several cross-border regions that should be evaluated in terms of self-learning and self-determining individual development trajectory of a pedagogue as a dominant value.

\section{Results of the study and their discussion}

The analysis of axiological issues of the education problems let this research organize a hierarchy of the threefold model of the task-oriented pedagogy, technology and knowledge content as a theory for the education space project of culture self-determination of the individual of a pedagogue. As is the case, the dominant values understood as generally accepted ideas of people about the goals, and the ways to be achieved and prescribed to certain socially accepted ways of behavior, are considered as the ideas to create the basis for all moral principles, and an individual system of socially and culturally significant values established in each social system [1,2,3].

At the first stage the aim is to provide the main concepts of this approach where both culture and education become the basic factors of the development of modern civilization and cooperation of all social systems where the process of forming universal values, world humanitarian culture and multi/poly/culture education is underway [1].

By the same token, another dominant value area of interaction between education and culture is the relationship between traditions and innovations in the ways of transmitting values from generation to generation; culture and education/instruction institutions with traditionally established systems carry out the process of transferring knowledge, experience and elements of human culture $[2,3,8,11,12]$.

Currently, it is increasingly culture ideas, and language component as an integrative humanistic trend in education constitute the core of the aims, knowledge content, pedagogy and technology, methods of training and retraining education of pedagogues that are updated and upgraded for strengthening their influence on the specifics of all types of human education, on the organization of the educational process in schools and universities $[5,6,8$,$] .$

And there presented the comprehensive model composed of three main concepts of CSD identified as:

Concept Sphere One - poly/lingua professional education spaces based on the value priorities, recurrent education as a value, and organized in the frameworks of culture events, communicative situations, and project and problem-solving rhizome like pedagogy.

Concept Sphere Two - polylingua intellect, polylingua status and polylingua thesaurus of the individual identified as positive linguistic and communicative strategies (patterns) of both a student and a teacher.

Concept Sphere Three - programming, planning, mentoring and fostering the students' concept sphere to obtain empirical data on the investigation of the students' needs and aspirations, interests and fruitful results in linguistic capacity, methodology of FLT and motivation for CSD in terms of the dominant values identified as the culture and creativity mission of a pedagogue in the poly/culture education. 
Thus, these theoretical and methodological concept spheres constitute the basic requirements for the professional development education spaces for culture self-learning of the individual in the process of ELT in the classroom. They are proposed for consideration and discussion to verify the model of CSD of the individual [1].

At the second stage of the research the goal is to study and generalize the conditions and possibilities for the Tutorials as a form of self-determined learning with practices and principles rooted in andragogy in professional education spaces of cross border regions, and distant education where learners are highly autonomous and self-determined for the emphasis is placed on development of the learner capacity and capability with the goal of producing learners who are well-prepared for the complexities of today's workplace.

Framework One. To fulfill this task FLT (foreign language teaching) on the basis of regional Institutes of In-Service Teachers Training and Retraining becomes particularly relevant, and is determined by the following factors: a) increasing requirements for the level of training of specialists in the context of modernization of education; b) needs of enterprises and organizations for highly qualified specialists who possess high level of professional competence development doable to carry out professional activities at the International level; c) the main purpose of FLT is seen in forming a level of communicative competence sufficient to carry out full-fledged communication in the situations of professional foreign language discourse, along with general competencies, which compose a set of social and personal qualities for carrying out professional activities at a highly qualified level and be responsible for the results.

Framework Two. To apply a novel approach to Pedagogy, Technology, and Knowledge Content, we set goals and analyze the results obtained independently to acquire knowledge for further development (self-determined and self-learning values). Independent work of the individual does not mean an increase in extracurricular load, but an increase in the level of formation of knowledge and skills obtained in the course of independent study of the information, Knowledge Content (dominant value of the education spaces) for individual development trajectory. As is the case, in the context of novel requirements for re/training of specialists there is an increasing need for novel ways and means to optimize training for improving the professional skills and competences. Tutorials as a technology is one of the most effective forms to organize regional development education spaces, and improve professional competencies in the field of professionally-oriented teaching of the individual.

At the third stage of this research is aimed for introduction of the tutorial practices into educational process of distant specifics and analysis of the results. The two module professional program under consideration is an important advantage of modular training as a comprehensive approach to individualization and variability of training, expanding educational opportunities, activating the independence of students, in our case, teachers of foreign languages, reducing the duration of training and improving the quality of professional education. In the course of training students (FL teachers) are to improve their competencies: PC-2 "is able to use modern methods and technologies of teaching and diagnostics" and PC5 "is able to provide pedagogical support for socialization and professional self-determination of students". As a result of the implementation of the Model, we present three more frameworks for consideration and verification in the training sessions.

Framework Three. To make the most of the problem-solving professional training to be adaptable to a multicultural society, to exchange new techniques and methods of teaching English using multimedia technologies. All the above-mentioned aspects of professional development programs affect foreign language education as a dominant value because any foreign language is able to combine four aspects, which constitute cognitive (knowledge of foreign culture and language as its component), development (development of various abilities, and speech \& thinking mechanisms), education (education of moral qualities of the 
individual) and learning (mastering the skills to speak, read, write, listen in a foreign language) ( Passoff, 2000).

Frameworks Four. To make the most of the regional component of the FLT standard the first module reflects the Knowledge Content covering the following topics: The regional component. The necessary Knowledge Subject taught within the requirements of primary and secondary education, implemented basic education programs, applied training packages. Methods of FLT::standard requirements for primary and secondary education. Methods of FLT: ICT. Education opportunities and features of modern computer tools: SubjectPedagogy computer software: FLT education. Subject: the requirements of Federal state educational standards; basic general education program; its history, and role in the world culture and science.

By the same token, the training program identifies the following lingua didactic tutorials within humanitarian activities named Pedagogy and Technology, covering the topics under consideration: Planned result. Competences and practical experience. Lingua didactic activities. Means and methods of professional activity of FLT teachers. Regularities of the processes of teaching and learning FLs in accord with the requirements of experience: methods of professional activity of FLT teachers.

Framework Five. To be adaptable, an annually updated corpus of additional training programs for teachers is a must for recurrent professional development, training and retraining of non-specialists, tutorial support in the format of individual consultations, online seminars of the pedagogical community, internships and workshops), that allow to create optimal opportunities for taking part/partnership in national and regional educational projects, and to present the projects on topical issues of education, in the format of educational recommendations, manuals and other publications in collaboration with the staff of the Department (articles, expert opinions, training programs, etc.).

As a result of the research in the frames/concepts of the comprehensive value model educators make the most of culture practices that become a result of successful humanitarian self-organization of the system, forming:

Ability to use textbooks, teaching aids and didactic materials on a foreign language to develop new teaching materials on a particular topic.

Experience in using textbooks, teaching aids and didactic materials on a foreign language to develop new teaching materials on a particular topic. Ability to use achievements of domestic and foreign methodological heritage, modern methodological directions and concepts of teaching foreign languages to solve specific methodological problems of a practical nature.

Experience in using achievements of domestic and foreign methodological heritage, modern methodological directions and concepts of teaching foreign languages to solve specific methodological problems of a practical nature.

Ability to critically analyze the learning process and learning materials in terms of their effectiveness.

Experience in critical analysis of the learning process and learning materials in terms of their effectiveness.

The overall results of the test tasks obtained in final analysis are shown in the table 1 to clarify the problem statement and the area for research and reconstruction in terms of CSD of the individual of pedagogues.

Table 1. The final analysis' overall results of the test tasks.

\begin{tabular}{|c|c|c|c|}
\hline Year, $\%$ & $\mathbf{2 0 1 5}$ & $\mathbf{2 0 1 7}$ & $\mathbf{2 0 1 9}$ \\
\hline $0-60 \%$ & $10 \%$ & $8.5 \%$ & $5 \%$ \\
\hline $61-70 \%$ & $34 \%$ & $31 \%$ & $15 \%$ \\
\hline $71-80 \%$ & $26 \%$ & $36.5 \%$ & $35 \%$ \\
\hline $81-100 \%$ & $20 \%$ & $24 \%$ & $45 \%$ \\
\hline
\end{tabular}


Thus, the obtained results of the scientific and methodological work made it possible to correct the Model of CSD of the individual in the polyculture and polylingua spaces, the constructs, and the frameworks at the final stage of the study, as well as to outline prospects for the teacher's participation in regional events to harmonize interaction in the professional information and education spaces. The authors' threefold dominant values model of culture approach proposed as a theory intended for emerging the technology in distance education, and for guiding distance education practices and the ways that distance educators is valid in discovering the devices for delivering the instructions used for novel communication technologies including webinars, Internet, on-line classes, social media, etc.

In this regard five main frameworks composed of the most important issues are presented for consideration within two stages of the study. In particular, we note that the evidence of the effectiveness of the proposed model is real events in the regions (Novosibirsk, Volgograd, Rostov-on-Don), where over the past five years, the annual work has been carried out on the dissemination of cultural humanitarian practices of tutorial origin in the background of increasing migration processes to solve the problem of cultural interaction. The annual local and large-scale regional events aimed at humanizing and harmonizing interaction are held with the participation of educators who take part in the programs under consideration. These issues find their realization via implementation of the comprehensive value model of CSD of the individual in one's concept sphere as an integrative characteristic of the elements of the polyculture and polylingua professional spaces of cross-border regions where the transition to the culture paradigm that means the transformation of the educational process into the interaction of equal participants of the education process, with a re-emphasis on the importance of the individual personal development and self-realization, creativity, culture self-determined learning, etc, is more vivid, and has to be thoroughly guided.

\section{Conclusions}

Professional education of Russian Federation has changed, and the need for highly qualified specialists who can independently and competently with high level of self-responsibility, self-determined attitude to self-learning via life is of primary importance to bring strategic "fruits" to the society. The significance of solving professional issues of CSD in terms of dominant values of the individual for scientific educators and practitioners is increasing in accord with the Federal state educational standard students' training that involves the formation of their competencies ensured by the competitiveness of the graduates, taking into account the requirements of the International labor market and opportunities for recurrent education of professionals. One of the tools for improving the system and independent assessment of the quality of education and training is the participation in professional skill competitions under the guidance of the tutors in the frameworks of the Tutorials of humanistic origin.

The growth of interest in spiritual culture of the individual, the development of his social activity pointed out by Academician, E. V. Bondarevskaya (2012), is considered to be a significant sign of forming the humanitarian space in the society where the focus of attention is on culture and education. Therefore, it can be stated that in the era of a total digital information environment (network communities, interest groups, etc.), entering the space of polyphonic interaction of people, different sub/cultures, different attitudes and life values, different language traditions, in the process of "language self-determination" as an integrative component of culture self-determination of the individual is even more relevant for education itself as a cultural phenomenon, requiring special attention to the problems of humanitarian organization and self-organization. While the goal is the realization of the personality through various languages of education (verbal and non-verbal, natural and artificial, languages of academic subjects, individual language of a personality, etc.), man as a system of relations 
with the environment is considered as an integral component of the process of mastering culture values and ethical norms for the formation of moral and professional conduct in a harmonious civilized society.

\section{References}

1. N.E. Bulankina, Humanitarian self-organization of the individual: philosophical reflection (Novosibirsk, 2013)

2. T.N. Korneenko, Domestic and foreign pedagogy 1(65), 7-19 (2020)

3. M.L. Levitsky, Izvestiya VSPU 10, 4-9 (2019)

4. S.A. Nelyubov, Siberian teacher 1(122), 19-24 (2020)

5. D. Nunan, Designing Tasks for the Communicative Classroom (Cambridge University Press, 1994)

6. Yu.L. Semenova, Scientific research in Education 12, 49-53 (2010)

7. H.G. Widdowson, Discourse Analysis (Oxford University Press, 2007)

8. A.N. Yakovleva, S.A. Dmitryeva, Pedagogical University Bulletin 4, 113-118 (2017)

9. M. Campbell, Open Journal of Social Sciences 6, 67-73 (2018)

10. M.S. Ivanov, M.S., Yanitsky, Siberian pedagogical journal 9, 78-84 (2012)

11. A. Scharle, A. Szabo, Learner Autonomy (Cambridge University Press, 2000)

12. S. Wallace, Teaching, Tutoring and Training in the Lifelong Learning (Learning Matters Ltd., 2007)

13. D. Nunan, Syllabus Design (Oxford University Press, 1998)

14. https://http://www.consultant.ru/document/cons_doc_LAW_140174/ 